half of the hydriodate of potash three times a day.

14. The pain in the cardiac region is rather less acute; in other respects the same. Bled to $\frac{3}{3} x$, five grains of blue pill ordered twice a day; continue the potash in four-grain doses, omit the colchicum.

15. Blood buffed and cupped; pulse 108; pain slightly relieved in the back; dysunœa gone; bowels open.

18. Aching pain in the whole cardiac region; palpitations violent; bellows sound very loud aver the aorta; pulse 106 , jerking. Bleed to $5 \times \mathrm{x} j$, and increase the hydriodate of potash to five grains; the blood was cupped and buffed; the pulse was lowered to 96 . Pain less.

20. The mercury has slightly affected the mouth, he is better. Discontinue the pills.

25. During the day he is more free from pain, but it returns at night with great severity in the cardiac region. Increase the potash to six grains.

23. He has been tolerably free from pain since the last report, until this morning, when he complained of the recurrence of pain in the cardiac region, with smarting along the spine; the palpitations are occasionally violent; dyspnoea; pulse 120 ; increase the potash to eight grains. Bled to $5 \times 5 y$.

May 21. Since the last report he has been occasionally free from pain, while sometimes the symptoms have assumed all their original violence. $\mathrm{He}$ has been cupped several times to $\overrightarrow{3} x$, from which he has experienced much benefit. The pain is more of an aching character than it was, and he is now considerably better. The hydriodate has been gradually increased to ten-grain doses.

June 12 . Since the last report he has not been quite so well. Increase the dose of the bydriodate to fifteen grains, and take ten grains of the pil. hydrarg. every night.

July 14 . Has been taking mercury since the last report. His gums are now tender, and the pills were ordered to be omitted. During the last month he has been occasionally very free from pain, but subject to palpitations on the least exertion. He has been also very excitable, the pulse rising to 120 whenever he was spoken to. He now takes 20 -yrain doses of the hydriodate of potash.

July 28. The mouth was kept pretty sore until a few days since. He is now much better, and has no pain; the action of the aorta is still heard to be strong, but it has lost the bellows sound.

Angust 3. Discharged.

Dr. Elliotson remarked on this case that of course he could not state positively that arganic disease of the aorta did not exist, but he was inclined to believe that that vessel was only inflamed. He had once seen a case of inflammation of the vessels of the right side, including the subclavian and the common carotid. He attributed some of the benefit which the patient bad derived, to the hydriodate of potash, but of course the advantages of the antiphlogistic remedies which were also employed must not be underrated. He thought that a strong proof that the disease was merely inflammatory was to be found in the very decisive benefit which the patient had derived from the loss of blood. The patient was liable to a return of the complaint, and the remedies must be continued for some time longer; but as he had become so much better, he could with propriety be made an out-patient.

\section{MEDICAL POOR-LAW CONTRACTS.}

To the Ellitor.-Sir,-I beg to transmit to you a copy of a Petition to the House of Commons, signed by 100 medical practitioners of Buckinghamshire and of towns bordering on the county. The petition is now in the hands of the Marquis of Chandos, and will shortly be presented.

I have the honour to be, Sir, Your most obedient servant, Robert Ceelt.

Aylesbury, Aug. 5, 1835.

(Together with a copy of the petition,in which the petitioners earnestly complain to the House of Commons of the proceedings of the Poor-law Commission. ers, and beseech its interference to procure a remedy for the grievances detailed therein, -we have received a copy of a memorial addressed to the Poor-law Commissioners, thus introduced:-

"At a meeting of Medical Practitioners of Buckinghamshire and of the neighbouring towns in the adjoining counties, lately held at Aylesbury, which afterwards formed itself into the 'Buckinghamshire Medical Association,' it was resolved,"That the injurious tendency of the recent arrangements arlopted by many of the boards of guardians, for the purpose of obtaining medical attendance for the sick. poor, should be made known, and the following Memorial addressed to the Poorlaw Commissioners."

(This Memorial, which is excellent in its, terms and objects, we have not space to insert in our present number without abridgment. The following, however, is ar analysis of its contents:--) 
The memorialists express their concern that no efficient medical aid is secured to the poor in sickness. The memorialists then proceed to say, that for years parochial medical assistance, dictated by a spurious economy, has not justified a lope of success, or of adequate remuneration,-vicious competition, opposing interest to duty, taking the place of unobjectionable practice. The memorialists sub. mit, that the late medical proceedings of many boards of guardians must terminate in injury and disappointment,-in inconvenient appropriation and inadequate division of the niedical duties, ending in fatal consequences to the sick, - the rate of payment proposed being altogether disproportionate to the services required of the nicdical attenciant, and conceived in total disregard of his social claims and his moral and legal responsibilities. The memorialists therefore earnestly complain, that the alternative of submitting to the introduction of strangers, who are necessarily ignorart of the nature and extent of their dutiss, is harsh, unprovoked, and oppressive. The memorialists consequently hope that the commissioners will reconsider the subject, and direct such regulations as shall be beneficial to the sick poor, satisfactory to the public, and fair and just to the medical profession.

Dated Aylesbury, June 20, 1835, and signed, on behalf of the meeting, by Rовт. CEELY, chairman.

The following Answer to this Memorial was returned by the Poor-law Commissioners, after acknowledging the receipt of the Memorial :-

"The Commissioners consider that it is perfectly impracticable for the boards of guardians to scrutinize the motives, whether honourable or dishonourable, of candidates for medical offices; but they must presume that, in any offer, the candidate sufficiently protects his own interest and that of his profession; whilst the guardians are bound to protect the interests of the rate-payers by selecting the most advantageous offers to be procured by open competition; and they are equally bound, in duty to the rate-payers, to the paupers, and to your profession even more particularly, to throw the situation open to the whole profession.

"Signed, by order of the Board,

"E. ChADwICK, Secretary."

\section{Petition.}

To the Honourable the Commons of the United Kingdom of Great Britain and Ireland in Parliament assembled, the Petition of the undersigned Medical Practitioners of Buckinghamshire, and of towns in the adjoining counties,
Humbly showeth, that your petitioners, being legally qualified Practitioners in Medicine and Surgery, believe -

That the medical profession renders to society services of the highest value, and that the remuneration of them in the ag gregate is an inadequate indemnity for the great expense of medical education, and the laborious duties and onerous responsibilities incurred.

That the profession has long been compelled to make great sacrifices in the discharge of its parochial duties to the sick poor, not mercly by reason of the noto. rious insufficiency of the stipend, but from the system of medical contracts adopted by the anthorities, which has been justly productive of reproach to thern, of scandal to the profession, and injury to the poor.

That the altered appropriation, and the insufficient division, of the medical duties in several unions, under the direction of the Poor-Law Commissioners, have removed from the establishod practitioners the main inducements to make the sacrifices above mentioned.

That these duties, thus rendered more laborious, and considerably more difficult of execution, are proposed to be met by a still lower rate of payment; it therefore becomes impossible for qualified persons to undertake then with the hope of doing justice to the sick and credit to themselves.

That the authorities perceiving the reluctance of established practitioners to undertake what it is obvious they are unable to perform, without greater sacrifices than society as at present constituted has a right to expect, have in most instances threatened, and in many effected the introduction of young and inexpe. rienced persons from a distance, necessarily unacquainted with the nature and extent of the duties to be performed, and to which they must in most instances be physically incompetent.

That those practitioners who have deemed it expedient to yield to these threats, have done so in the full conviction that the legislature, which has manifested its solicitude for the public good by properly enforcing of late years on inedical practitioners a more efficient and expensive qualification, will not when respectfully appealed to, fail to protect them from such degradation, injustice, and op* pression.

That your petitioners entertaining the highest respect for the laws and government, helieving that it was not the design of the legislature to render the operation of the Poor-Law Amendment Bill oppres- 
sive to any class of the community, and satisfied that the inevitable consequences of these arrangements must be disappointment to their authors, injustice and de. gradation to the medical profession, and noglect and suffering to the sick poor, feel it their daty humbly bat earnestly to complain to your Honourable House, beseeching your interforence for the removal of a system not less opposed to soind policy than at variance with the interests of science and the dictates of justice and humanity.

And your petitioners will ever pray, \&c.

We regret to find, by the newspapers, that the building formerly occupied by HunTen, and latterly known as the Windmill-street Theatre, has been materially injured by a calanitous fire, which occurred on Tnesday night last, in the neighbourrood of Rupert-street. The sittings of the Westminister Melical Society have of late years been held in the anatomical museum.

\section{CORRESPONDENTS.}

J. S.-It was evidently a mistake of the printer, and shoul i hive been printed " viudicatory."

The letter of Mr. Barlienan wants an adilress.

The cases amd remarks on Creosote, forwarded by Mr. Taylor. shall appear in THE LaN(iET of vext wcek. The wish expressed in his private note shatl be complied with.

The communication of "No. 2 " did not reach us, we are sorry to say, unil too late for insertion this wetk.

A correspondent inquires whether any cases of the malignant cholera have récently occurred in Lon:lon. We reply that we have accounts of none. With regard to his remarks on some reports said to have issued from a building called the "Free Hospital," we can only say that newspapar announcements of metropolitan cases of cholera are very likely to be attempts to obtain notoriety for cholera pữ-shops.

\section{METEOROLOGICAL REPORT.}

(Extract from a Meteoroloyical Jourial kept at Hiy, Wyconble.

Lat. $51^{\circ} 37^{\prime} 41^{\prime \prime}$ North, Long. $31^{\circ} .15^{\prime \prime}$ West.)

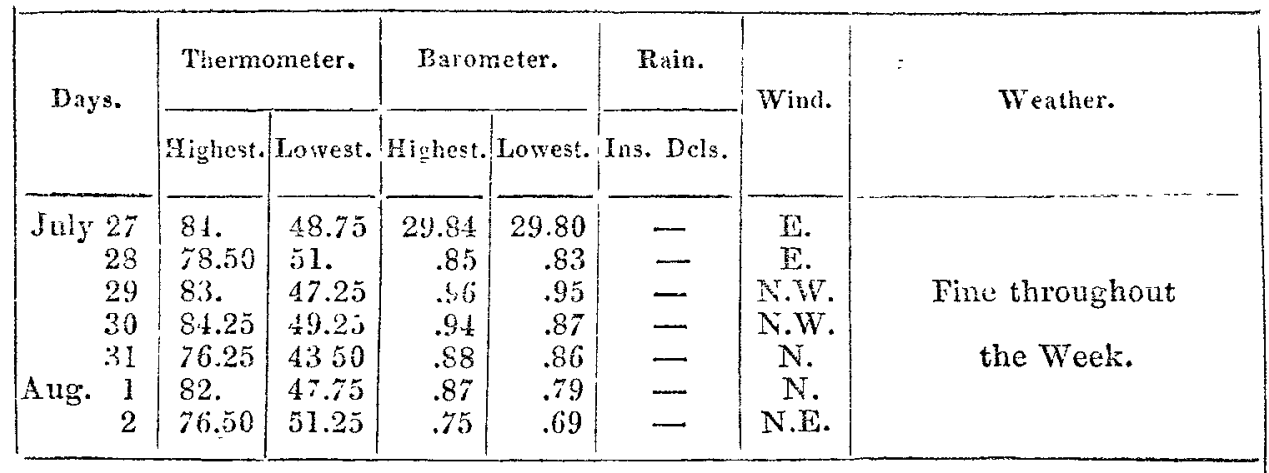

July 28,1835 .

W. JACKSON.

Montlily Observations for July. - Quantity of rain fallen during the month in inches and lecinals, 1,14375. Unlike the last month, the range of the barometer was exceedingly small. The maximum was below those of the same month for the last five years. The minimum was above those which have occurred since 1827, and the mean was higher than in July 1833 and 1834. There was less rain than in any July sinee 1826 ; it did not amount to one-sixth part of what fell in the July of 1834 . The whole quantity of rain which has fallen since the commencerrent of the present year, is very nearly the same as foll during the same period of time in the last year. The month was not so hot as the July of 1834, but with that exception has been warmer than any July since 1826. A thunder storm was experienced on the 2nd of August, the lightning was sonetimes very vivid, and about one-third of an inch of rin fell.

Augnst 5th, 1835.

W. JACKSON. 